Nuevos ensayos de sociología y comunicación

\section{Octavio Uña}

\section{Madrid: Editorial Universitas}

En este libro, el catedrático de Sociología de la Universidad Rey Juan Carlos (URJC) Octavio Uña nos ofrece el resultado de su vasta experiencia como docente, planteando un compendio de distintas líneas de trabajo en el ámbito de la sociología y la comunicación.

Escrito con una vocación claramente didáctica, tal como el propio autor expresa ya en el prólogo, Octavio Uña ha concebido este libro dividido en dos partes temáticas: una primera dedicada a la epistemología y la teoría, y una segunda a las mediaciones y construcciones sociales. Como el común denominador de ambas es que se encuentran a medio camino entre la sociología y la comunicación, en este libro se enlazan conceptos e ideas concernientes a ambas disciplinas.
En su primera parte, el libro comienza con un análisis del concepto y las teorías asociadas a los modelos de comunicación, desde su definición hasta su concreción en diferentes líneas teóricas, en el que se resaltan sus enlaces con los procesos comunicativos concretos, así como sus virtudes y críticas. El autor orienta al lector acerca de la situación de las distintas corrientes teóricas dentro del eje formado por el empirismo y el racionalismo epistemológico, por un lado, y su orientación macrosocial y microsocial, por el otro; se visibiliza, así, el posicionamiento lógico de las distintas corrientes, lo que facilita la comprensión de cada línea de pensamiento y del sentido de las divisiones teóricas de la ciencia social.

Más adelante, y con Edgar Morin como pretexto, Octavio Uña aprovecha para reflexionar acerca del pensamiento epistemológico de la sociología, aportando información que responda a la pregunta no resuelta: «¿cómo debe funcionar la sociología como ciencia?» 
Con tal propósito, el autor pone sobre la mesa elementos para que el lector ubique las «ciencias sociales» dentro del ámbito de la «ciencia», así como para facilitar la comprensión respecto de la relación de la sociología consigo misma, a partir de los diversos conceptos y autores que han tratado esta cuestión. Con tal propósito, pone sobre la mesa clarividentes explicaciones acerca de qué es una teoría; qué visiones y clasificaciones existen para las mismas (desde la división de Kaplan en teorías jerárquicas y concatenadas hasta la división en teorías globales y de rango intermedio); cómo se pueden examinar o probar; la crítica de Bourdieu al exceso de teoría o manualización del conocimiento, y los debates entre Luhmann y Habermas al respecto.

De modo similar procede con el asunto de los «hechos sociales» como elementos centrales de la ciencia social. A partir de una definición satisfactoria, Uña aborda el papel de los hechos sociales en la sociedad y en relación con la ciencia, mientras destaca en este sentido la figura de Durkheim como disciplinador de la sociología dentro de la ciencia, cuestión que permitió superar la especulación o ideología propia de Comte o Spencer.

La primera parte finaliza con una reflexión acerca de la teoría sociológica, en la que aborda, de manera sintética, distintas aproximaciones teóricas a la disciplina, así como la posibilidad de que dichas aproximaciones pudieran converger en una gran teoría común. También plantea una explicación del desarrollo de la disciplina sociológica a partir de las reflexiones de tres de sus padres fundadores: Durkheim, Weber y Pareto, desgranando algunos de los rasgos principales de su pensamiento y su impacto en el posterior desarrollo de la ciencia social.

La segunda parte del libro, Mediaciones $y$ construcciones sociales, empieza con un capítulo dedicado a los conceptos, lenguajes y metáforas, en el que el autor abandona el lenguaje puramente pedagógico - no porque aparque la orientación docente del libro- por una prosa más cercana y literaria, un cambio de registro intencionado para entablar un diálogo con los autores que cita como si fueran conocidos o amigos (dándolo a entender así en algún caso), e introducir así la importancia del lenguaje como transmisor $y$, sobre todo, estructurador del conocimiento $y$ la ciencia; $y$, por lo tanto, elemento central en el devenir de la sociedad. Cita a Schaff o Wittgenstein para reforzar la idea de la necesidad del lenguaje en el desarrollo del pensamiento.

Acto seguido, Uña retoma el lenguaje puramente pedagógico para describir los principales actores del proceso comunicativo - emisores y receptores$y$ los distintos elementos que influyen en dicho proceso y lo dotan de sentido. Recupera, así, las diversas líneas de pensamiento que han aportado ideas $y$ reflexiones a la comprensión de la co- 
municación, e incide en las distintas formas mediante las cuales estas perspectivas han abordado dichos elementos: del emisor funcionalista, entendido como individuo o colectivo cuyos mensajes despiertan o solicitan la atención del público, al emisor marxista, sometido a la profesionalización (pág. 162) y, por lo tanto, bajo el yugo de las organizaciones en torno a la comunicación con estructuras muy complejas (pág. 162).

Plantea una estructura similar a la hora de hablar de los medios de comunicación de masas como constructores de identidad y cultura, y como integradores y homogeneizadores sociales de la cada vez más individualista y atomizada sociedad capitalista. Para su clasificación teórica, Octavio Uña se sirve de la distinción de Thayer, quien plantea una división entre medios de comunicación primarios, secundarios y terciarios en función de la distancia comunicativa y de la capacidad de alcanzar números cada vez mayores de receptores, siendo los primarios los más cercanos y con menor alcance (comunicación cara a cara), y los terciarios, por el contrario, los más lejanos y con mayor alcance (comunicación mediatizada por instrumentos para la emisión y la recepción).

Esta división le sirve como punto de partida para una revisión de la evolución histórica de los medios de comunicación y una relectura de los mismos pasada por la lupa de la teoría de McLuhan, acuñador del concepto de aldea global, para coronar la sección/ capítulo con las aportaciones de otros autores sobre la comunicación, como Benjamin, Brecht o Enzensberger. El libro concluye con una revisión de las aportaciones del interaccionismo simbólico al mundo de la comunicación, que está centrado en Blumer, Harré y Secord, y Homans y Blau, con la sombra de Mead sobrevolando transversalmente a todos ellos.

El resultado es un libro claramente didáctico, con numerosas aportaciones significativas para la comprensión de la comunicación y la sociología, que puede perfectamente servir de material de apoyo para docentes en estas materias. Por otro lado, la propia lógica del libro como compendio de ensayos lleva a que cada capítulo tenga un robusto sentido interno y resulte, en sí mismo, un material redondo, con principio y final. Más allá de su respectiva temática común, el contenido general reviste un profundo interés para todo aquel que desee profundizar en el campo de la sociología de la comunicación, enriqueciéndose del conocimiento acumulado y compilado por el profesor Uña.

\section{David Dueñas i Cid}

